\title{
THE ROLE OF NIGHT VISION EQUIPMENT IN MILITARY INCIDENTS AND ACCIDENTS
}

\author{
C.W. Johnson \\ Department of Computing Science, University of Glasgow, Glasgow, G12 9QQ, Scotland.
}

\begin{abstract}
Night vision devices provide enormous benefits. They enable personnel to carry out operations under conditions that would not otherwise be possible. However, these benefits carry considerable risks. For instance, individuals often become over confident about their ability to use image intensification and infrared devices. In consequence, the use of night vision equipment is an increasingly common factor in military incidents and accidents. This paper uses an analysis of incident and accident data to identify requirements for the successful deployment of night vision equipment. It is argued that these applications must be integrated more closely with existing navigational systems. The successful application of this technology also depends upon adequate risk assessment and team-based training.
\end{abstract}

Key words: Accident analysis, Risk, Decision Making, Night Vision Equipment.

\section{INTRODUCTION}

There are two main classes of night vision devices. Image intensification (I) systems enhance the lighting that is available within the existing environment. Infrared (IR) devices, in contrast, will typically use heat emissions to identify objects that cannot otherwise be detected using available light sources. These systems support a wide range of military operations that would not otherwise have been possible. However, the additional capabilities provided by night vision devices also create new risks. Night operations continue to result in significantly more accidents and incidents than their daytime counterparts (Ruffner et al, 2004). We are interested in the role that night vision equipment plays in incidents and accident because many armed forces have faced recent increases in the 
number and frequency of adverse events. For instance, the number of aviation fatalities from mishaps across all US Department of Defense personnel rose from 65 in 2001 to 82 in 2002. In May 2003, Defense Secretary Rumsfeld focused concern on these and similar statistics across the US military: "World-class organizations do not tolerate preventable accidents. Our accident rates have increased recently, and we need to turn this situation around" (Gilmore, 2003). He set the challenge to "to reduce the number of mishaps and accident rates by at least $50 \%$ in the next two years".

\section{A BRIEF OVERVIEW OF NIGHT VISION}

Military personnel, typically, rely on their visual sense during most operations. Safe flight relies upon good depth perception for landing, good visual acuity is critical if pilots are to identify terrain features. Drivers of land-based vehicles rely on depth perception to judge whether or not they can cross ditches, visual acuity is important in many aspects of land-based navigation. However, color vision, depth perception, and visual acuity all vary depending on which of the three different types of vision soldiers must rely on in a particular operation. Photopic vision occurs with high levels of illumination. The cones concentrated in the center of the fovea are primarily responsible for vision in bright light. High light condition will bleach out the rod cells that support peripheral vision. However, the reliance on cones produces sharp image interpretation and color vision using photopic vision. In contrast, mesopic vision, typically occurs at dawn and dusk or under full moonlight. This relies on a combination of rods and cones. Visual acuity steadily decreases with declining light. Color vision degrades as the light level decreases, and the cones become less effective. Mesopic vision is often regarded as the most dangerous if personnel do not adapt to the changing light conditions. As light levels fall, there will be a gradual loss of cone sensitivity. Operators should be trained to rely more on peripheral vision. If personnel fail to recognize the need to change scanning techniques "from central viewing to off-center viewing, incidents may occur" (Department of the Army, 2000). Scotopic vision is used under low-light level environments such as partial moonlight and starlight. Cones become ineffective, causing poor resolution of detail. Primary color perception during scotopic vision is shades of black, gray, and white unless the light source is high enough in intensity to stimulate the cones. A central blind spot, known as the night blind spot, also occurs when cone-cell sensitivity is lost. If an object is viewed directly at night, it may not be seen. If the object is detected, it will fade away when stared at for longer than two seconds. 
The human eye can adapt to low light. Biochemical reactions increase the level of rhdopsin in the rods. This controls light sensitivity. Individual differences again affect the rate and degree of adaptation. It can take between 30-45 minutes for most people to achieve their maximum acuity under low levels of light. Brief flashes, for instance from strobe lights, have little effect on night vision. However, looking at a flare or searchlight for longer than a second will have an adverse effect on most people. A number of other factors, such as smoking and individual differences, also adversely affect night vision. Night myopia arises from the way in which the visual spectrum is dominated by blue wavelengths of light. Nearsighted individuals viewing blue-green light at night typically experience blurred vision. Even personnel with perfect vision will find that image sharpness decreases as pupil diameter increases. Similarly, "dark focus" occurs because the focusing mechanism of the eye often moves toward a resting position in low light levels. Special corrective lenses can be used to address this problem for individuals who suffer from night myopia. Binocular cues stem from slight differences in the images that are presented to each of the operator's eyes. Low lighting can make it difficult for personnel to perceive any visible differences. The effect is increased when objects are viewed at a distance. Low light levels also affect a number of monocular cues for depth perception. These include geometric perspective, motion parallax, retinal image size, and aerial perspective. As we shall see, the problems of depth perception play an important role in the causes of incidents and accidents.

A number of training techniques can help maximize any remaining visual resources in low levels of light. For example, the following list summarizes the Canadian Army's (2004) guidelines for night observation:

1. Aim-off with the eyes - Never look directly at what is to be seen. For example, if the eye looks directly at a pin-point of light it will not see the outline of the tank from which the light is coming.

2. Do Not Stare Fixedly - The eyes tire rapidly at night so an object will disappear if it is looked at for a long time.

3. Avoid Looking at Any Bright Lights - Shield the eyes from parachute flares, spotlight or headlights. Dim flashlights and turret lights and blink when firing weapons.

4. Look Briefly at Illuminated Objects - The time spent glancing at lighted objects such as maps or illuminated dials must be kept to a minimum.

5. Do Not Scan Quickly - Move the eyes in a series of separate movements to give the eye a chance to pick up a target which will appear much slower than daylight. 
6. Limit Time Spent Scanning - Continuous scanning will cause the eye to partially black out. The eyes should be rested for 10 seconds every 2 minutes.

7. If Necessary Use Eyes Individually - If a lit area has to be observed, then protect the night vision of one eye by keeping it shut. One eye should be shut as an automatic reaction if a bright light suddenly appears.

\subsection{Image Intensification Systems}

Personnel can compensate for the limitations imposed by low light conditions either by training to make the most of their night vision or through the provision of night vision equipment. Image intensification systems support direct observations by amplifying low levels of ambient light. They do not 'turn night into day', nor do they compensate for many of the problems that affect vision in low light environments. Most image intensification systems perform poorly in total darkness. Amplification can range up to 35,000 times the available light. Higher amplification is associated with more expensive devices and can imply increased levels of distortion. The intensified image is, typically, viewed on a phosphor screen that creates a monochrome, video-like image, on the user's eyepieces.

Most image intensification systems are attached to the users' helmet. Early models included relatively heavy battery packs that restricted the users' head movements. This problem was exacerbated by the need to move the head because many devices offer a highly restricted field of vision between 40-60 degrees. A post action review of the Canadian Army's deployment in Kosovo found that "the current issue helmet and night vision goggles are not compatible and are painful to wear". (Canadian Army Center for Lessons Learned, 2001). Soldiers had to remove the devices to reduce the fatigue and frustration that built up during prolonged use. Image intensification equipment can also create problems in depth perception. Colour cues and binocular information are lost with many commercial systems. All of these limitations are being addressed by technological innovation. In particular, it is now possible to buy light weight and extended field of vision systems. These tend to be expensive and can be difficult to maintain under field conditions (Salazar and Nakagawara, 1999).

Visual acuity from night vision devices provides a vast improvement over human night vision. However, it is far from perfect. As with direct sight, higher levels of accuity are associated with closer, slower targets. The visual accuity offered by image intensification rapidly diminshes for objects over 400 feet away. Rain, clouds, mist, dust, smoke, fog all reduce accuity. For example, 'brown out' has contributed to a number of incidents where helicopter crews rely on images that are suddenly degraded by the 
dust that is brought up in the wash created by their rotors (Department of the Army, 2000). A recent incident involving a Canadian military helicopter in Bosnia providesa further illustration of these environmental problems (Canadian Air Force, 2002). Reports of adverse weather conditions initially convinced the crew to remain in Banja Luka. However, if they left immediately they calculatted that they could return to their base in Velika Kladusa within their eight hour flying limit. "We strapped on our night vision goggles after refueling and decided to go for it". They were seven miles from their destination when they noticed that the lights on the hills were no longer where they expected them to be. They also began to lose sight of the lights ahead of them using their night vision equipment. The cloud lowered until it engulfed the hills that surrounded them. They realized that they could not go back to Banja Luka and so were forced to follow the only open valley in sight. The presence of mines from previous conflicts meant that they could not simply set down in any available field (Canadian Air Force, 2002). The subsequent analysis of this incident identified the danger that crews will become unduly complacent about the support provided by night vision equipment under adverse meteorological conditions.

The performance of image intensification systems can be impaired by a number of external light sources. Looking at the moon has the same effects as looking directly at the sun under daylight lighting conditions. This creates problems when soldiers move toward a bright moon that is low on the horizon. The brightness of the 'ambient' light source degrades the intensified image. It will also cast deep shadows that can hide hazards, including excavated fighting positions. This creates considerable problems for drivers trying to locate these emplacements using night vision equipment (US Army Centre for Lessons Learned, 2001). External light sources can also support the use of image intensification equipment. For instance, city lights often provide useful illuminations especially if cloud cover reflects the available light back onto a scene. However, there is a risk that personnel will fixate on these external light sources. Many of the problems associated with image intensification systems stem from their operational environment. Vehicle instrument lights and cockpit displays can create "washout" or halo effects. In many road-based vehicles it is possible to turn-off instrument illumination. However, it is a complex and expensive task to alter cockpit lighting systems without compromising the daytime use of the aircraft. These problems are compounded because red lights are frequently used in speedometers and engine instruments. Night vision systems are often particularly sensitive to these sources. Personnel must also be trained not to use red-lens flashlights in situations where image intensification equipment 
is being used. In ground operations, oncoming headlights pose a major hazard because drivers must often use their goggles at times when other road users rely on their vehicle lights. These light sources can dazzle the wearer of a night vision device to the point where they will not see barriers and obstacles, including equipment or people. These are not the only source of light polution that affect the users of image intensification systems. Many aviation systems are sensitive to the anti-collision lights required by FAA regulations. These will be intensified to a point at which they can distract or even dazzle the wearer of an intensification system. Risk assessments should consider the range of problems that can arise with image intensification systems.

\subsection{Infrared and Thermal Imaging Systems}

Thermal imaging systems detect infrared radiation that is emitted by heat sources. Although the human eye cannot directly observe these signals, they can be focused in the same way as conventional light. Transducers detect the thermal emissions. Their output is then processed to represent the difference in temperature amongst the objects in a scene. Thermal contrast is then translated into a visual contrast that is, typically, represented in shades of gray on a monochrome display. In contrast to image intensification devices, infrared systems can be used in total darkness because they do not rely on the light reflected by an object. A further benefit is that thermal imaging systems avoid the "blooming" that occurs when strong light sources swamp intensification systems. Infrared devices also avoid some climatic problems. For instance, they can see through some types of fog. However, problems can arise under different environmental conditions. A wet runway may be cooled to such an extent that it appears to be further away than it actually is. High-humidity reduces thermal contrast and so will adversely affect image quality. Infrared systems cannot be used to identify precise details on remote objects, such as facial features, that are not distinguishable by different heat profiles.

Thermal imaging systems can be used in conjunction with infrared landing and searchlights. These tend to be most effective at low levels of illumination. If there are external lights then pilots tend to limit their scan to within the area directly covered by the searchlight. They have to be trained to expand their search on either side of the beam. Brownout can also occur when there are reflections from an infrared searchlight caused by the dust that is raised in a rotor wash. The heat emitted by infrared searchlights can help enemy personnel who may themselves be using night vision equipment. As with image intensification systems, individuals can quickly become fatigued through prolonged use of these devices. A recent Lessons Learned 

Accidents

review was conducted into the initial deployment of light armored vehicles. One of four main findings was that "Long periods of using thermal optics can lead to crew fatigue...this can be overcome by having the dismounts trained on the functions of the turret" (New Zealand Army, 2003).

\begin{tabular}{|l|l|l|}
\hline & FY95 & FY96 \\
\hline Day & 7.59 & 7.69 \\
\hline Night & 9.72 & 13.87 \\
\hline Night unaided & 6.37 & 9.31 \\
\hline Night aided & 11.28 & 15.80 \\
\hline Night systems & 17.15 & 22.54 \\
\hline Night goggles & 11.97 & 14.37 \\
\hline Total & 8.09 & 9.14 \\
\hline
\end{tabular}

\section{Table 1. Class A-C Rotary-wing Accidents per 100,000 flying hours}

\section{STATISTICAL STUDIES OF NVD MISHAPS}

Table 1 presents the results of a study by the US Army Safety Centre into the accident rate for various forms of night operation involving rotary winged aircraft. As can be seen, there is a lower accident rate for flights involving direct 'unaided' visual observations than there is for flights with this equipment. Such a counter-intuitive finding can be explained in a number of ways. It might be that the use of night vision equipment impairs situation awareness, distracts from the use of other information systems and hence increases the likelihood of an adverse event. Equally, it might be argued that these devices tend to be used under adverse meteorological and environmental conditions when accidents are more likely to occur anyway. These different hypotheses illustrate the problems involved in moving from simple correlations to more detailed causal explanations. For instance, the US Army's Black Hawk helicopter fleet has suffered more than 20 fatal accidents in its 27 year service history. Approximately half of these occurred while pilots were wearing night vision devices (Hess, 2002). However, the fact that an accident occurred while the crew were using this equipment does not imply that the incident was caused by these devices. It can be very difficult to assess the role that particular technologies play in an adverse event. This is especially problematic when crewmembers may have suffered psychological or physiological trauma. They may be unable or unwilling to discuss the details of their actions in the aftermath of an 
accident or near-miss incident. Further problems arise because these statistical studies do not consider those accidents under direct visual conditions that could have been avoided if the crew had been provided with night vision equipment.

Some attempts have been made to conduct a more detailed analysis of the accident statistics. For instance, Ruffner, Piccione and Woodward (1997) identified 160 US army accidents that were related to the use of night vision devices in ground vehicles between 1986-1996. Over two-thirds were attributable to three categories of terrain and roadway hazards: drop-offs greater than three feet $(34 \%)$, ditches of three feet or less $(23 \%)$ and rear collisions with another vehicle (11\%). 34\% involved the High Mobility Multipurpose Wheeled Vehicle (HMMWV), 18\% involved the M1 Abrams Tank and 14\% involved the M2/M3 Bradley Fighting Vehicle. The most commonly occurring environmental conditions that included dust (24\%), blooming from light source $(9 \%)$ and smoke $(8 \%)$. Braithwaite, Douglass, Durnford and Lucas (1998) conducted a similar study of aviation accidents that focused on spatial disorientation caused by the use of night vision devices in helicopter operations. They argued that the various limitations of night vision devices, including the issues of depth perception and orientation mentioned in previous pages, predispose aircrew to 'spatial disorientation'. They found that approximately $43 \%$ of all spatial disorientation mishaps occurred during flights that used night vision equipment. Only $13 \%$ of accidents that did not involve spatial disorientation involved these devices. An examination of the spatial disorientation accident rates per 100,000 flying hours revealed a significant difference between the rate for day flying and the rate for flight using night vision devices. They concluded that the use of night vision devices increased the risk of a spatial disorientation accident by almost five times.

\section{LACK OF NVD LEADING TO MISHAPS}

It is often argued that the provision of night vision devices would have prevented many accidents. Such counterfactual arguments can be illustrated by the loss of a US Marine KC-130. The aircraft crashed into a Pakistan hillside near Shamsi airfield. There were no approach lights or navigational aids. The KC-130 was not equipped with any night vision equipment. Helicopter operations and noise restrictions prevented the crew from using their preferred approach. However, other KC-130s had landed at the same airfield without problems. The crew was experienced and rested. They had all flown into the airfield before. The official report concluded that the 
crew had "stopped navigating with instruments" and relied on direct visual observations during their approach (Durrett, 2002). Several analysts, therefore, argued that night vision equipment would have helped to avoid the accident because direct visual observations had failed to identify the hazards (Vogel, 2002). After the crash, the Marines began to retrofit KC-130s with night-vision equipment and a GPS linked map-based navigation system. The official report insisted that while the provision of night vision equipment would have helped the crew, it would not necessarily have prevented the accident (Durrett, 2002).

The problems of using accident information to analyze the strengths and weaknesses of night vision technology can also be illustrated by litigation following a land-based training accident (Maryland Court of Appeals, 1999). A US Army Major was run over by a truck driven by 2 Maryland Army National Guardsmen during a training exercise. The Major belonged to an active duty unit that was evaluating the exercise. The accident occurred just after midnight, when the two guards drove their truck along a dirt road to pick up a patrol. The Major had remained seated in the roadway after he had finished evaluating another exercise. He made no apparent effort to move as the truck approached. The vehicle was driving under "blackout conditions" without headlights. Although one of the drivers had a set of night vision goggles, he was not using them. Neither soldier had received any training in their use. Neither saw the Major who suffered serious injuries that were exacerbated by a series of delays in his evacuation. He was transported to the wrong hospital and was eventually declared dead on arrival at the intended destination.

The National Guard determined that the Major's death was caused by his lack of situation awareness during night vehicle maneuvers. They argued that if the Major had been alert, he would have heard the truck. The accident was also blamed on resource limitations that prevented the National Guard from training troops to use night vision equipment. In contrast, the Army rejected lack of funding and training as reasons for the drivers not using night vision goggles. The accident was caused more by the driver's excess speed than the Major's inattention. The Major's widow sued the State and the Maryland National Guard for maintaining insufficient supplies of night vision goggles and for failing to provide training to the drivers in the use of night vision goggles. Maryland's Court of Appeals unanimously upheld a Montgomery County Circuit Court decision to reject the $\$ 6$ million lawsuit. This ruling illustrates the difficulty of using previous accidents to justify the introduction of night vision equipment. The judges' decision hinged on whether the court had jurisdiction over National Guard operational matters, including the provision of particular items of equipment. To establish 
negligence it was argued that a jury would have to decide how many night vision goggles should have been acquired. The jury might also have to consider how such vision equipment should have been allocated, what kind of training should have been provided and when it should have been offered etc (Maryland Court of Appeals, 1999).

\subsection{Night Vision Devices Contribute to Accidents}

In contrast to those mishaps that might have been prevented by night vision equipment, many mishaps directly stem from the provision of these devices. For example, existing night vision currency requirements in the US Army's Aircrew Training Manual state that aviators must fly at least one hour using night vision equipment every 45 days. A recent incident demonstrated that the minimum requirement is insufficient for many missions. A UH-60L instructor pilot had over 8,000 hours of rotary-wing experience. All the crewmembers had flown together many times in the past. Both pilots were qualified and current for the night vision goggle training mission. However, they both averaged less than 3 hours of night vision flight per month over the preceding 7 months. The Army Safety Centre (2003) report argued, "If any one of the conditions - low recent experience, dust, winds, or low illumination - had not been present, perhaps the accident would not have occurred. If the aircrew had more recent experience, they would have been better able to deal with the harsh environment. If the illumination had been better, their low recent experience might not have been a factor. If the conditions had not been as dusty, perhaps the crew would not have become disoriented". This illustrates how a number of adverse factors can combine to create the conditions in which an incident occurs. In other words, the use of night vision equipment plays a necessary but insufficient role in the accident. Sufficient conditions often exist when personnel rely on these devices in extremely hazardous environmental or meteorological conditions.

The complex nature of many night vision incidents can also be illustrated by an adverse event involving an officer with a motorized rifle platoon (US Army Centre for Lessons Learned, 2001). His unit was to occupy a battle position during a training exercise using an M551A1 Sheridan light tank. The officer's platoon was to move from their hiding positions to occupy prepared fighting positions. His orders included information about the safety requirements associated with zero illumination operations. The officer also had access to a compass, a map and a GPS receiver to assist with nighttime navigation. Although the officer was relatively unfamiliar with the area, the gunner had several years of experience on this range. Even so, they spent a number of hours driving around looking for their battle position. Standard 
operating procedures stated that the gunner should have dismounted to guide the driver when traveling cross-country in zero illumination. Instead, the officer used night vision goggles while his driver used a night sight. When they failed to find their fighting position, the officer was told to wait until first light before continuing the search. He carried on looking until the vehicle eventually overturned in the excavation. The officer was standing in the nametag defilade position and received fatal crush injuries. The Army Safety Centre argued that the crew relied too much on their night vision equipment as they searched for their battle positions. Soldiers must gain "an understanding and appreciation of the risk-management process and know that if the risks outweigh the benefits, then the mission should be a nogo" (US Army Centre for Lessons Learned, 2001).

\subsection{Risk management}

Risk management is the process of identifying and controlling hazards. The introduction of night vision technology can reduce the likelihood of some accidents whilst at the same time increasing the risks associated with other types of adverse event. Personnel are likely to conduct operations that would not have been attempted without the technology and which in retrospect ought not to have been attempted even with this additional support. Other risks stem from the limitations of the technology; these include visual illusions and the problems associated with environmental hazards. It is difficult to survey the risk 'landscape' in which night vision increases the likelihood of some hazards and diminishes the likelihood of others. For example, peacekeeping operations often present senior staff with complex decisions in which the use of night vision equipment forms part of a much wider set of concerns (Johnson, 2002). For example, the Canadian force in Somalia was involved in an incident that killed one Somali and wounded another (Canadian Department of National Defence, 1997). It was a turning point in Canadian involvement and forced significant changes in their rules of engagement. A Reconnaissance Platoon observed two Somalis walking around the wire of the Canadian Engineer's compound. The detachments had overlapping arcs of observation and fire. Infrared chemical lights were used to mark their positions in a way that was visible through night vision equipment but invisible to the naked eye. It appears that the 2 men fled after being challenged. They were then were shot at from behind. One was immediately wounded and the other was subsequently shot dead by another part of the patrol. Night vision equipment only played a small part in this incident. The soldiers' interpretation of their rules of engagement and the leadership of the Reconnaissance Platoon were identified as primary 
causes. However, the subsequent inquiry did examine the decision to use night vision equipment. It was argued that if the compound had been better illuminated with conventional lighting then local civilians, especially petty thieves, would have been less inclined to approach the installation. Shortly after the incident, the Engineers constructed a light tower. This was perceived to have significantly reduced the problem of petty theft. However, the shootings may also have had a deterrent effect. The key issue here is that additional lighting was not initially installed because it would have interfered with the use of night vision goggles. The risk of nighttime friendly fire incidents was perceived to be of paramount importance. The shooting showed that this underestimated the risks of using night vision equipment in close proximity to the local civilian population (Canadian Department of National Defence, 1997).

\subsection{Night-Vision Accidents and Training}

US Army driver training requirements cover the use of night vision equipment in AR 600-55. This is supported by training circulars such as TC 21-305-2 Training Program For Night Vision Goggle Driving Operations and FM 21-305. Support is provided through a range of courses designed for specific vehicles as well as more general training, including TC 1-204 Night Flight Technique and Procedures. Much of this material has been informed by the lessons of previous adverse events. For example, a series of accidents led to a reminder being issued across the US Army that bright lights from vehicle headlights and other sources will drive the goggles' gain down to the point that everything else in the field-of-view all but disappears. In addition, if the bright light exposure continues for 70 seconds $(+30$ seconds), the PVS-7s will turn off. Similarly, officers were reminded that the natural illumination provided by the moon is often critical for image intensification systems and so missions should be planned to take into account the 15 degrees per hour change in the height of the moon as it waxes and wanes (US Army Safety Center, 2003a). The US Army also operates systems for learning lessons about the use of night vision equipment within particular operational contexts. In particular the insights gained from Operations Desert Shield and Desert Storm together with rotations in Kuwait helped to develop training materials that were put to use in more recent conflicts (US Army Safety Center, 2003b). Desert operations in Iraq again illustrated the importance of integrating information obtained from night vision equipment with accurate data from GPS applications. In particular, operational experience reinforced the need for personnel to be trained to keep the lenses clean and the goggles stored safely when not in use. Sand and dust accounted for a higher than expected attrition rate for most units 
with access to these devices. Pilots were accustomed to dry lakebeds and scrub in their National Training Centre but were less prepared for the impact of shifting sand dunes and extreme temperatures on night vision equipment. For instance, "the authorized airspeed for nap of the earth flight is 40 knots, but an aircraft flying in zero illumination at 25 feet in sand dunes should fly just ahead of effective transitional lift...Just keep in mind that at airspeeds below ETL, you may encounter rotor induced blowing sand" (US Army Safety Center, 2003b). Operation experience also identified a number of visual illusions with night vision equipment. These devices can provide an impression of a false horizon when light-colored areas of sand surround dark areas, especially when other environmental factors, including dust and haze, also obscure the horizon. Desert conditions often also lack the visual markers and reference points that support accurate height perception. Under such circumstances, ground lights can often be mistaken for the lights of other aircraft or even stars. Lack of features and relatively slow speeds can also persuade pilots that they have stopped moving even though the aircraft is actually moving forward. These illusions can be so persuasive that individuals will still fall prey to them even though they have been trained to recognize that they can occur. Greater attention has recently been paid to team and crew coordination as a potential barrier to incidents and accidents. For instance, the Army Safety Center's Southwest Asia Leaders' Safety Guide emphasizes the need to synchronize crew observations and communications in order to combat some of the problems created by these illusions. Guidance is provided on scanning responsibilities for pilots and non-rated crewmembers in different types of flight.

The provision of training does not always match up to the standards that are claimed in many official publications. For instance, one of the lessons learned during the Canadian deployment in Bosnia was that more ground forces need to be trained in a wider range of this equipment. One of the participants in this deployment observed that "personnel were unable to train on the variety of Night Vision Devices that were eventually made available to us in theatre... not having this equipment available prior to deployment meant that we had to utilize valuable time to train personnel on equipment that they should have been familiar with before they arrived". Some of the equipment that they were expected to use only arrived six weeks after their deployment. However, the units were able to overcome these limitations. The Post Action review found that this equipment helped dismounted patrols in the towns and villages. The technology provided local inhabitants with a "dramatic" example of their fighting capability. This was claimed to have deterred crime and established credibility (Canadian Army Centre for Lessons Learned, 2001). 
We have not considered the problem of fratricide. Many friendly-fire incidents directly stem from the use of night vision devices. Brevity prevents a more sustained analysis of these adverse events. Many of the issues are similar to those that lead to more general mishaps.

\section{CONCLUSIONS AND FURTHER WORK}

This paper has looked beyond the advertising and hype that surrounds many night vision devices. Our analysis has shown the complex role that image intensification and thermal imaging plays in military accidents and incidents. Some investigators have argued that these devices were a primary cause of military mishaps. Conversely, it has also been argued that the availability of night vision equipment would have prevented other accidents from occurring. A key conclusion is that the successful introduction of these systems depends upon a range of supporting factors. These include complementary technologies, such as GPS systems. The supporting infrastructure also depends upon appropriate training. This should help users to familiarizing themselves with individual devices but must also consider the ways in which teams of soldiers interact to overcome the limitations of existing technology. Greater emphasis should also be placed on formal risk assessment before these devices are deployed in military operations ${ }^{1}$.

Ruffner, Piccione and Woodward (1997) have shown that existing night vision training helps drivers to identify ditches and other road conditions. It does not, however, help them to identify those depressions and other hazards that they have shown to be the cause of most night vision accidents. The accidents and incidents identified in this paper have supported many of the criticisms put forward by Ruffner et al. Several of the coalition partners in the Gulf were forced to use accelerated procurement to ensure that sufficient devices were made available to troops prior to the conflict. The UK Ministry of Defense (2003) issued an Urgent Operations Requirement action. Further work is required to determine whether this successful acquisition shortly before the conflict led to accelerate training procedures and whether this, in turn, led to the accidents and incidents predicted by Ruffner and his colleagues.

\footnotetext{
${ }^{1}$ This work was partly funded by EC RTN ADVISES (CT 2002-00288).
} 


\section{REFERENCES}

M.G. Braithwaite, P.K. Douglass, S.J. Durnford and G. Lucas, The hazard of spatial disorientation during helicopter flight using night vision devices. Journal of Aviation and Space Environmental Medicine, (69)11:103844, 1998.

Canadian Air Force, A Dark and Stormy Night, Flight Comment, No 2, pp 6-7, Spring, 2002.

Canadian Army, Armour School Master Lesson Plan, Armored Reconnaissance Specialist Course: Observation, 2004.

Canadian Army Centre for Lessons Learned, Night Vision in Kosovo, The Bulletin, (8)1:611, April 2001.

Canadian Dept of National Defence, The Somalia Inquiry Report; Chap 5 March $\mathbf{5}^{\text {th }}$ Incident, 1997. http://www.forces.gc.ca/site/Reports/somalia/vol5/V5C38B e.asp

W.D. Durrett, Report into the Loss of a KC-130 at Shamsi Pakestan, January $\mathbf{9}^{\text {th }} 2002$, US Marine Corps, San Diego, 2002

G.J. Gilmore, 'We Don't Need to Lose People' to Accidents, DoD Personnel Chief Asserts, US Department of Defence, DefenseLink, June 2003.

P. Hess, Army Identifies Soldiers Killed in Crash, UPI, December 2002. http://www.upi.com/view.cfm?StoryID=20021213-124412-7962r

C.W. Johnson, Risk and Decision Making in Military Accident Reporting Systems. In L. Johnson (ed.) Proceedings of Human Factors 2002, Melbourne, Australia, 2002.

C.W. Johnson, (2003). Handbook of Incident Reporting, Glasgow University Press, Glasgow, Scotland.

Maryland Court of Appeals, The Estate of Andrew Burris, et al. v. The State of Maryland, et al. No. 130, Sept. Term, 1999. Opinion by Wilner, J.

New Zealand Army, Lessons Learned from Initial Deployment of the Light Armored Vehicle (LAVIII), LAV Update Number 3, August 2003.

J. W. Ruffner, D. Piccione and K. Woodward, Development of a night driving simulator concept for night vision image intensification device training. In Proc of Enhanced and Synthetic Vision Conference, SPIE 11th International Symposium on Aerospace/Defense Sensing, Simulation, and Controls, Orlando, Vol 3088. PP. 190-197, 1997.

J.W. Ruffner, J. D., Antonio, D.Q. Joralmon and E. Martin, Night vision goggle training technologies and situational awareness. Proc of Advanced Technology Electronic Defense System Conference/Tactical Situational Awareness Symposium, San Diego, CA. 2004.

G.J. Salazar and V.B Nakagawara, Night Vision Goggles in Civilian Helicopter Operations, Federal Air Surgeon's Medical Bulletin, Fall 1999.

US Army Centre for Lessons Learned, An M551A1 in the Wrong Hands, Countermeasure, Volume 29, Number 2, February 2001,

US Army Centre for Lessons Learned, NVG Currency, A Perishable Skill - Currency is Not Proficiency, Flight Fax, Vol. 31, Number 2, February 2003.

US Army Centre for Lessons Learned. Fight at Night and Survive, Countermeasure Vol 24. Number 4, April 2003a.

US Army Centre for Lessons Learned, Night Vision Goggles Desert Operations Lessons Learned - 13 Years in the Making, Flight Fax, Vol. 31, Number 4, April $2003 \mathrm{~b}$.

US Army Safety Centre, U.S. Army Accident Information, Aviation Accident Statistics for the Current Fiscal Year, As of 19 January 2004.

US Department of the Army, Aeromedical Training for Flight Personnel, Washington, DC, 29 September 2000, Field Manual 2-04-301 (1-301) 
S. Vogel, Marine KC-130 That Hit Mountain Had No Night Vision, Washington Post, Sunday, February 17, 2002; Page A17. 